\title{
Okul Öncesi Dönemde Çocuğa Evde Sunulan Desteğin Okuma Yazmaya Hazırlık ve Matematik Becerileri Bağlamında İncelenmesi
}

\author{
Hatice Gözde Ertürk Kara*
}

Makale Geliş Tarihi: 09/05/2018

Makale Kabul Tarihi: 02/01/2019

DOI: $10.35675 /$ befdergi.422261

$\ddot{O} z$

Bu araştırmada, çocukların okula hazır olmalarında önemli etkisi bulunan okuma yazmaya hazırlı ve matematik becerilerinin evde ailesi tarafindan ne düzeyde desteklendiği incelenmiştir. Bununla beraber, çocuğa ilişkin çeşitli özelliklerin (yaş, cinsiyet, okul öncesi eğitim alma durumu, okul öncesi eğitim alma süresi) evde sunulan destek üzerindeki etkisi araştırılmıştır. Araştırma, betimsel tarama modelindedir. Araştırmanın örneklemini, Türkiye'nin en büyük ili olan İstanbul ve küçük bir Anadolu şehri olan Aksaray'da okul öncesi eğitim kurumuna devam eden 110 çocuk oluşturmuştur. Ailelerin okuma yazmaya hazırlık ve matematik becerilerini evde orta düzeyde desteklediği belirlenmiştir. Ailelerin çocukların okuma yazmaya hazırlı ve matematik becerilerini destekleme düzeylerinin çocuğun cinsiyetine, yaşına ve doğum sırasina göre farklılık göstermediği belirlenmiştir. Okul öncesi eğitimi alma durumu ve okul öncesi eğitimi alma süresi ise çocukların evde gerçekleştirdikleri yapılandırılmış etkinlikler üzerinde etkili olmuştur. Çocukların okuma yazmaya hazırlı becerilerinin evde desteklenme durumu ile matematik becerilerinin evde desteklenme durumu arasında anlamlı bir ilişki olduğu görülmüştür.

Anahtar Kelimeler: Okul öncesi dönem, aile, okuma yazmaya hazırlı, matematik

\section{Examination of Parent Support in terms of Children's Early Literacy and Mathematics Skills}

\begin{abstract}
This study aims to examine parents' support of their children regarding early literacy and mathematics skills at home. Additionally, the effect of some variables such as gender, age, status of taking early childhood education, duration of early childhood education) on parents' support of children's early literacy and mathematics skills at home were examined. Screening model was preferred in the study. Sample of the study consist of 110 children who study at early childhood education centers in Aksaray and Istanbul. It was determined that parents' support their children early literacy and mathematics skills at home in medium level. Parents' support level at home didn't show a significant difference according to children's gender, age and order of birth. Status of taking early childhood education, duration of early childhood education variables made a significant effect on parents' support in structured activities sub dimension. And lastly, a significant relation was determined between parents' support of their children's early literacy skills at home and parents' support of their children's mathematics skills at home.
\end{abstract}

Keywords: Early childhood education, parents, early literacy, mathematics

\footnotetext{
* Aksaray Üniversitesi/Eğitim Fakültesi/Temel Eğitim Bölümü, Aksaray, Türkiye, gozde86erturk@ gmail.com, ORCID: 0000-0001-7895-8938

Kaynak Gösterme: Ertürk-Kara, H.G. (2019). Okul öncesi dönemde çocuğa evde sunulan desteğin okuma yazmaya hazırlık ve matematik becerileri bağlamında incelenmesi. Bayburt Eğitim Fakültesi Dergisi, 14(27), 87-105. https://doi.org/10.35675/befdergi.422261
} 


\section{Giriş}

Aile, çocukların yaşamla ilgili ilk deneyimlerini kazandıkları, kendilerine güven duygularını geliştirdikleri, sosyalleşmeyi ve topluma uygun tutum ve davranışlar sergilemeyi öğrendikleri ortamdır. Çocuklar bu ortamda kendilerini okul hayatına hazırlayacak beceri ve yeteneklerini geliştirme fırsatı da bulmaktadır (Ertürk Kara, 2017).

Çocuğu ailesinden sonra en fazla zamanını geçireceği yer olan okula hazırlama, yalnızca kişilik ve sosyal becerilerinin geliştirilmesi olarak algılanmamalıdır. Ailenin çocuğu bilişsel, duygusal, motor gelişimi gibi alanlarda da destekleme sorumluluğu vardır. Ancak, ince motor becerileri gelişmiş bir çocuk ilkokul sıralarına oturduğunda kalemi rahatlıkla tutabilir. Bu nedenle okula hazır olma, hem ailenin hem de okul öncesi eğitim kurumunun bütüncül bir yaklaşımla ele alması gereken bir olgudur (Crnic ve Lamberty 1994; Snow 2006). Okuma yazmaya hazırlık ve temel matematik becerileri ise çocuğu okula hazırlayan beceriler arasındadır. Okuma yazmaya hazırlık becerileri, sözel dil becerileri, alfabe bilgisi, fonolojik farkındalık, kelime bilgisi, aynı sesle başlayan ya da aynı sesle biten kelimeleri fark etme ve yazılı kelimeler arasında konuşulan kelimeleri ayırt etme şeklinde sıralanabilir. Matematik becerileri ise, boyut ile ilişkili kavramlar (büyük/küçük gibi), tanıma, adlandırma, eşleştirme, karşılaştırma, gruplama, sınıflandırma, sayılar, toplama, çıkarma ve bölme, modelleme, geometri ve görsel mantık, ölçme ve grafik oluşturmadır (Uyanık ve Kandır, 2010). Çocuk bu becerileri evde ve okulda kurduğu etkileşimler yoluyla öğrenmektedir. Bu nedenle, ailenin çocuğun bu becerileri kazanarak sonraki eğitim kademelerine hazır hale gelmesindeki sorumluluğunun farkında olması gerekmektedir. Öğretmenin ise çocuğun öğrenmesinde kalıcı etki yaratabilmek için öncelikle aileyi tanıması gerekmektedir. Lynch, Anderson, Anderson ve Shapiro“ a göre (2006) öğretmen bu aşamada iki tip aile ile karşılaşmaktadır. Bunlardan ilki, çocuğun öğrenmesinde sorumlu olduğunu bilen, çocuğun gelişimine uygun çeşitli yöntemler ile okuldaki uygulamaları evde de destekleyen aile tipidir. Bir diğer aile tipi ise çocuğun öğrenmesindeki tek sorumlunun öğretmen olduğunu düşünen ailelerdir. Bu aileler, sadece beceriye odaklanarak çocuğa kâğıt kalem kullandıkları çalışma sayfaları gibi yapılandırılmış etkinlikler sırasında yardımcı olma görevleri olduğunu düşünmektedir. Nitelikli bir okul öncesi eğitim süreci için öğretmenin aileyi tanıması, ailenin bakış açısı ve beklentilerini ortaya koyması ve ihtiyaçlarına yönelik çalışmalar ile ailenin çocuğun öğrenmesindeki rolünün farkında olmasını sağlamalıdır. Bu süreç, ailelerin öğretmenden ve eğitimden gerçekçi, çocuğun gelişimine ve bireysel farklılıklarına uygun beklentilerinin olmasını ve çocuğun eğitimi hakkındaki konuları öğretmenle tartışabilecek yeterliliğe ulaşmaları açısından oldukça önemlidir (MEB, 2013a). Nokali, Bachman ve Votruba-Drzal'a göre (2010), ailenin eğitime katılımı okul ve aile arasındaki etkileşimin bir ürünüdür ve ailelerin öğretmenin sınıfta gerçekleştirdiklerinden haberdar olmaları evde sunulan desteği arttırmaktadır. 
Alan yazında pek çok araştırma, ailelerin okul ile işbirliği içinde bir tutum sergileyerek çocuğa evde sundukları desteğin çocukların okuma yazmaya hazırlık ve matematik becerileri üzerinde etkili olduğunu göstermektedir (Akıncı Coşgun ve Tezel Şahin, 2018; Huntsinger, Jose, Liaw ve Ching, 1997; Kleemans, Peeters, Segers ve Verhoeven, 2011; LeFevre vd., 2009; Lefebvre, Trudeau ve Sutton, 2011; Sénéchal ve LeFevre, 2002; Wood, 2002; Van Voorhis, Maier, Epstein ve Lloyd, 2013). Bu araştırmada ailelerin evde çocuklara sundukları desteğin okuma yazmaya hazırlık ve matematik becerileri bağlamında ne düzeyde olduğunu belirlemek amaçlanmaktadır. $\mathrm{Bu}$ desteğin düzeyinin belirlenmesinin ailenin ve çocuğun ihtiyaçlarının belirlenmesi ve ihtiyaca yönelik aile eğitiminin yapılabilmesi açısından yol gösterici olacağı düşünülmektedir. Bununla beraber, çocuğa ilişkin çeşitli özelliklerin (çocukların cinsiyeti, yaşı, doğum sırası, okul öncesi eğitimi alma durumu ile okul öncesi eğitimi alma süresi) evde sunulan destek üzerinde anlamlı bir farklılık yaratıp yaratmadığı da incelenmiştir.

\section{Yöntem}

\section{Araştırmanın modeli}

Bu araştırmada nicel araştırma yöntemlerinden betimsel tarama modeli kullanılmıştır. Tarama modelindeki araştırmalar, geçmişte ya da günümüzde hala var olan bir durumu, var olduğu şekliyle betimler (Karasar, 2009). Betimsel tarama modelinde amaç, bir topluluğa ait olan bir grup bireyin herhangi bir konu hakkındaki görüşleri, inanışları, tutumları veya bilgi düzeylerini betimlemektir (Fraenkel, Wanner ve Huyn, 2012). Bu araştırmada, ailelerin evde çocuklara sunduğu destek okuma yazmaya hazırlık ve matematik becerileri bağlamında incelenmiştir

\section{Katılımcilar}

Araştırmanın örneklemi kolay ulaşılabilir örnekleme yöntemi ile belirlenmiştir. Buna göre, Türkiye'nin en büyük ili olan İstanbul ve küçük bir Anadolu şehri olan Aksaray'da okul öncesi eğitim kurumuna devam eden 110 çocuk araştırmanın örneklemini oluşturmuştur.

\section{Veri Toplama Araçları}

\section{Kişisel bilgi formu}

Araştırmacı tarafından geliştirilen kişisel bilgi formunda çocuğa ve ailesine ilişkin bilgi almak amacıyla çocuğun cinsiyeti, doğum tarihi, doğum sırası, daha önce okul öncesi eğitim alıp almama durumu, okul öncesi eğitimi alma süresine ilişkin sorular yer almaktadir. 


\section{Çocukların evde akademik becerilerinin desteklenmesi ölçeği}

Çocukların evde matematik ve okumaya ilişkin becerilerinin ne düzeyde desteklendiğini değerlendirmek amacıyla Huntsinger, Jose \& Luo (2016) tarafindan geliştirilmiş, Türkçe'ye uyarlaması Ertürk Kara ve Kılıç Çoksoyluer (2017) tarafindan yapılmıştır. Bu araştırmada ölçeğin, üçüncü bölümde yer alan üç alt boyut ve toplam 17 maddeden oluşan Matematik alt ölçeği kullanılmıştır. Matematik alt ölçeğinde yer alan alt boyutların iç tutarlılık katsayıları sırasıyla Formal Matematik Etkinlikleri için .78, Informal Matematik Etkinlikleri için .77 ve Oyun/ Oyuncaklar için .76'dır. Matematik alt ölçeğinin tamamına ilişkin iç tutarlılık katsayısı ise .90 'dır. $\mathrm{Bu}$ araştırmada alt ölçeğin tamamına ilişkin iç tutarlılık katsayısı .71 olarak hesaplanmıştır.

\section{Okuma yazmaya hazırlık anketi}

Nebrig (2007) tarafından geliştirilen ve Altıparmak (2010) tarafından Türkçe'ye uyarlanan Okuma Yazmaya Hazırlık Anketi dörtlü likert tipi sorulardan oluşan iki bölümden oluşmaktadır. Ailelerin ankette yer alan okuma-yazmaya hazırlık etkinliklerini ne kadar önemli buldukları (A Bölümü) ve evde okuma yazmaya hazırlık etkinliklerini ne sıklıkla gerçekleştirdikleri (B Bölümü) değerlendirmektedir. Her iki bölüm de iki alt boyuttan oluşmaktadır; Yapılandırılmış Etkinlikler alt boyutu genellikle çocuğa okuma veya hikaye hakkında soru sormak gibi günlük bir rutinde ebeveyn ile çocuğun arasında gerçekleşen 22 okuma yazma etkinliğinden oluşmaktadır. Yapılandııılmamış Etkinlikler alt boyutu ise genellikle okulda yapılan etkinliklere benzer ek materyaller gerektiren 23 okuma yazma etkinliğinden oluşmaktadır. A Bölümünde aileler 45 okuma yazmaya hazırlık etkinliği için (1) Çok önemli değil, (2) Biraz Önemli, (3) Çok önemli ama kesinlikle gerekli değil ve (4) Kesinlikle önemli ve gerekli seçenekleri arasından; B Bölümünde ise bu etkinlikleri gerçekleştirme sıklıklarını (0) Nadiren veya hiçbir zaman, (1) Ayda bir veya iki kere, (2) Haftada bir veya iki kere, (3) Haftada üç veya daha fazla kere seçenekleri arasından seçerek yanıtlamışlardır. Ölçeğin tamamının iç tutarlılık katsayısı .97 'dir. $\mathrm{Bu}$ araştırmada ise .93 olarak hesaplanmıştır.

\section{Veri Toplama Süreci}

Araştırmada kullanılan veri toplama araçları çalışma grubunda belirlenen okullardaki öğretmenlere ulaştırılmıştır. Öğretmenler, araştırmaya katılmaya gönüllü olan ailelerden gelen formları araştırmacıya posta aracılı̆̆ıyla ulaştırmıştır.

\section{Verilerin Analizi}

Çocukların Evde Akademik Becerilerinin Desteklenmesi Ölçeğinde yer alan Matematik alt ölçeği ile Okuma Yazmaya Hazır Anketi'nden elde edilen veriler üzerinde betimsel analiz gerçekleştirilerek en düşük, en yüksek, ortalama ve standart sapma değerleri hesaplanmıştır. Okuma Yazmaya Hazırlık Anketi'nde yer alan maddeler için yüzde değerleri verilmiştir. Bağımsız değişkenlerin matematik ve 
okuma yazmaya hazırlık puanları üzerindeki etkisini incelemek için öncelikle grup içi normallik testleri gerçekleştirilmiş ve Kolmogorov katsayısı incelenmiştir. Buna göre, verilerin normal dağılım göstermediği görülmüştür. Analize, non parametrik testlerden Mann Whitney U ve Kruskall Wallis Testleri ile devam edilmiştir. Ailelerin evde sundukları matematik becerilerine ve okuma yazmaya hazırlığa ilişkin destek arasındaki ilişki için spearman brown korelasyon katsayısı hesaplanmıştır.

\section{Bulgular}

$\mathrm{Bu}$ bölümde, çalışma grubunu oluşturan çocuklara ve ailelere ilişkin demografik bilgileri ile Okuma Yazmaya Hazırlık Anketi ve Çocukların Evde Akademik Becerilerinin Desteklenmesi Ölçeği'nden elde edilen bulgulara yer verilmiştir.

Çalışma Grubunu Oluşturan Çocuklara Ve Ailelere İlişkin Demografik Bilgiler Tablo 1.

Çalışma Grubunu Oluşturan Çocuklara ve Ailelere İlişkin Demografik Bilgiler

\begin{tabular}{lcc}
\hline Cinsiyet & f & \% \\
Kız & 63 & 57.3 \\
Erkek & 47 & 42.7 \\
Yaş & & \\
$40-60$ ay & 27 & 24.5 \\
$60-80$ ay & 83 & 75.5 \\
Doğum sırası & & \\
En büyük & 21 & 19,1 \\
En küçük & 47 & 42.8 \\
Tek & 20 & 18.2 \\
Ortanca & 22 & 20 \\
Okul öncesi eğitimi alma durumu & & \\
Aldı & 26 & 30.9 \\
Almadı & 84 & 69.1 \\
Okul öncesi eğitimi alma süresi & & \\
İlk kez & 84 & 76.4 \\
Bir yıl & 20 & 18.2 \\
İki yıl & 6 & 5.5 \\
Evde yaşayanlar & & \\
Anne ve Çocuk & 1 & 0.9 \\
Anne, baba ve Çocuk & 95 & 96.4 \\
Diğer & 14 & 12.7 \\
Anne öğrenim durumu & & 1.8 \\
Okuma yazma bilmiyor & 2 & 30.9 \\
İkokul & 19 & 30.9 \\
Ortaokul & 34 & \\
Lise & 34 & \\
\hline
\end{tabular}




\begin{tabular}{lcc}
\hline Yüksekokul & 10 & 9.1 \\
Üniversite & 11 & 10 \\
Baba öğrenim durumu & & \\
Okuma yazma bilmiyor & 1 & 0.9 \\
İlkokul & 23 & 20.9 \\
Ortaokul & 9 & 8.2 \\
Lise & 53 & 48.2 \\
Yüksekokul & 6 & 5.5 \\
Üniversite & 17 & 15.5 \\
Lisansüstü & 1 & 0.9 \\
\hline
\end{tabular}

Tablo 1 incelendiğinde, çalışma grubundaki çocukların \%57.3'ünün kız, \%42.7'sinin erkek olduğu görülmektedir. Çocukların \%75.5'inin yaşı 60-80 ay arasında değişmektedir. \%42.8'i evin en küçük çocuğudur. Çocukların yarıdan fazlası (\%69.1) daha önce okul öncesi eğitim almamıştır. Daha önce iki yıl okul öncesi eğitim alan çocukların oranı $\% 5.5$ 'tir. Çocukların çok büyük bir bölümü çekirdek aile içinde yaşamaktadır, geniş aile ile yaşayan çocukların oranı \%12.7'dir. Annelerin yarıya yakını (\%30.9) ortaokul ve lise mezunudur. Babalar ise \%48.2 oranında lise mezunudur.

\section{Ailelerin Okuma Yazmaya Hazırlık Etkinliklerine Verdikleri Öneme İlişkin Bulgular}

Bu bölümde ailelerin okuma yazmaya hazırlık etkinlikleri arasından kesinlikle çok önemli ve gerekli buldukları ilk on ve son on etkinlik ve yüzde değerleri verilmiştir.

Tablo 2.

Ailelerin Okuma Yazmaya Hazırlık Etkinlikleri Arasından Kesinlikle Çok Önemli ve Gerekli Buldukları İlk On Etkinlik ve Yüzde Değerleri

\begin{tabular}{ll}
\hline Maddeler & \% \\
\hline $\begin{array}{l}\text { Çocuğunuza okurken bilinmedik kelimelerle karşılaşıldığında durup bunları } \\
\text { anlatmak veya tanımlamak }\end{array}$ & 77.3 \\
$\begin{array}{l}\text { Çocuğun ismindeki harfleri gösterip tanıtmak } \\
\text { Hikâye okurken veya okuduktan sonra çocuğu hikâye hakkında konuşmaya } \\
\text { teşvik etmek }\end{array}$ & 75.4 \\
$\begin{array}{l}\text { El kaslarını güçlendirmek için kil, lego veya blok gibi oyuncaklarla beraber } \\
\text { oynamak }\end{array}$ & 74.6 \\
$\begin{array}{l}\text { Bir işi yaparken (örneğin; alışveriş yapma, yemek pişirme veya banyo } \\
\text { yapma) ne yapıyor olduğunuzu anlatmak }\end{array}$ & 74.6 \\
$\begin{array}{l}\text { Çocuğu kendi adını yazmasına teşvik etmek } \\
\text { Çocuğu yazarken veya resim yaparken pastel boya, tebeşir, kurşun, keçeli }\end{array}$ & 72.8 \\
$\begin{array}{l}\text { veya tükenmez kalem gibi değişik malzemeler kullanmasına teşvik etmek } \\
\text { Çocuğu en azından 2 dakika süresince bir konu, bir kişi veya o an ne yaptığı } \\
\text { hakkında konuşmaya teşvik etmek }\end{array}$ & 70 \\
\hline
\end{tabular}


$\begin{array}{ll}\text { Belgesel ve eğitici programları beraber izleyip tartışmak } & 70\end{array}$

Çocuğun, çizdiğiniz harflerin üzerinden kalemle geçmesini istemek

Ailelerin Okuma Yazmaya Hazırlık Anketi'nde yer alan etkinlikler arasından en çok (\%77.3) "çocuğunuza okurken bilinmedik kelimelerle karşılaşıldığında durup bunları anlatmak veya tanımlamak" maddesini kesinlikle gerekli ve önemli buldukları belirlenmiştir. $\mathrm{Bu}$ maddeyi çocuğun ismindeki harfleri gösterip tanıtmak (\%75.4) maddesi izlemektedir.

\section{Ailelerin Evde Çocuklarıyla Birlikte Okuma Yazmaya Hazırlık Etkinliklerini Gerçekleştirme Sıklıklarına İlişkin Bulgular}

Bu bölümde ailelerin evde çocuklarıyla birlikte okuma yazmaya hazırlık etkinliklerini gerçekleştirme sıklığına ilişkin olarak, Tablo 4'te haftada üç veya daha fazla kez yapılan ilk on etkinliğin yüzde değerlerine, Tablo 5 'te ise nadiren yapılan veya hiçbir zaman yapılmayan ilk on etkinliğin yüzde değerlerine yer verilmiştir.

Tablo 3.

Ailelerin Evde Çocuklarıyla Birlikte Haftada Üç veya Daha Fazla Kez Yaptıkları İlk On Okuma Yazmaya Hazırlık Etkinliği ve Yüzde Değerleri

\begin{tabular}{|c|c|}
\hline Maddeler & $\%$ \\
\hline $\begin{array}{l}\text { El kaslarını güçlendirmek için kil, lego veya blok gibi oyuncaklarla beraber } \\
\text { oynamak }\end{array}$ & 43.6 \\
\hline Çocuğun ismindeki harfleri gösterip tanıtmak & 42.7 \\
\hline $\begin{array}{l}\text { Çocuğu en azından } 2 \text { dakika süresince bir konu, bir kişi veya o an ne yaptığ } 1 \\
\text { hakkında konuşmaya teşvik etmek }\end{array}$ & 41.6 \\
\hline $\begin{array}{l}\text { Çocuğu yazarken veya resim yaparken pastel boya, tebeşir, kurşun, keçeli } \\
\text { veya tükenmez kalem gibi değişik malzemeler kullanmasına teşvik etmek }\end{array}$ & 37.5 \\
\hline a teşvik etmek & 35.5 \\
\hline Tekerlemeli oyunları oynamak & 34.5 \\
\hline $\begin{array}{l}\text { Televizyonda, radyoda veya sokakta duyduğunuz kafiyeli şarkıları } \\
\text { söylemek }\end{array}$ & 34.5 \\
\hline oyuncaklarla veya bilgisayar oyunlarını beraber oynamak & 32.7 \\
\hline $\begin{array}{l}\text { Çocuğunuza okurken bilinmedik kelimelerle karşılaşıldığında durup bunları } \\
\text { anlatmak veya tanımlamak }\end{array}$ & 31.8 \\
\hline $\begin{array}{l}\text { Evcilik oyunlarında çocuğu listeler hazırlamaya teşvik etmek (garsonculuk } \\
\text { oynarken "sipariş alma" veya evcilik oynarken "alışveriş listesi" hazırlama } \\
\text { gibi) }\end{array}$ & 31.8 \\
\hline Belgesel ve eğitici programları beraber izleyip tartışmak & 31.8 \\
\hline
\end{tabular}

Okuma Yazmaya Hazırlık Anketinde bulunan etkinlikler arasından ailelerin çocuklarıyla birlikte evde en sık yaptıkları etkinliğin "el kaslarını güçlendirmek için kil, lego veya blok gibi oyuncaklarla beraber oynamak" olduğu görülmektedir. Bu etkinliği "Çocuğun ismindeki harfleri gösterip tanıtmak" (\%42.7) izlemektedir. 
Tablo 4.

Ailelerin Evde Çocuklarlyla Birlikte Nadiren Yaptıkları ya da Hiçbir Zaman Yapmadıkları İlk On Okuma Yazmaya Hazırlık Etkinliği ve Yüzde Değerleri

\begin{tabular}{ll}
\hline Maddeler & \% \\
\hline Çocuğa bir kelimenin veya bir ismin ilk sesini değiştirmesini istemek & 59.1 \\
mesela, Murat'ı surat olarak değiştirmek) & \\
İki kelime söyleyip bunların kafiyeli olup olmadı̆̆ını sormak & 51.8 \\
$\begin{array}{l}\text { Çocuktan bir kelime veya ismin hece sayısına göre el çırpmasını istemek } \\
\text { Birkaç kelimenin içinde hangisinin farklı sesle başladığını sormak }\end{array}$ & 50 \\
(“masa, moda, kavun, müzik” gibi) & 49.1 \\
Dil sürçmeli tekerlemeler söyletmek & 48.8 \\
Çocuğu kitaplara bakması için kütüphaneye veya kitapçıya götürmek & 46.4 \\
Harfleri öğretmek için tahta veya mıknatıslı harfler kullanmak & 45.5 \\
Harflerle alfabe ile ilgili kitapları okumak & 34.5 \\
Çocuğun “yazdığı” bir şeyi okumasını istemek & 33.6 \\
Çocuğunuza okurken okuduğunuz kelimeleri parmakla göstermek & 32.7 \\
Kafiyeli kitaplar okumak & 32.7 \\
\hline
\end{tabular}

Ailelerin Okuma Yazmaya Hazırlık Anketinde yer alan etkinlikler arasından çocuklarıyla birlikte evde nadiren yaptıklarını ya da hiç yapmadıklarını ifade ettikleri etkinliğin \%59.1 oranında "çocuğa bir kelimenin veya bir ismin ilk sesini değiştirmesini istemek mesela, Murat'1 surat olarak değiştirmek)" olduğu görülmektedir. Bu etkinliği "İki kelime söyleyip bunların kafiyeli olup olmadığını sormak" (\%51.8) izlemektedir.

\section{Ailelerin Evde Çocuklarıyla Birlikte Okuma Yazmaya Hazırlık ve Matematik Etkinliklerini Gerçekleştirmelerine İlişkin Betimsel Analiz Sonuçlarına İlişkin Bulgular}

$\mathrm{Bu}$ bölümde ailelerin evde çocuklarıyla birlikte okuma yazmaya hazırlık ve matematik etkinliklerini gerçekleştirmelerine ilişkin olarak, ortalama, en yüksek, en düşük ve standart sapma değerleri hesaplanmıştır. Tablo 5 'te bu değerler verilmiştir.

Tablo 5 .

Ailelerin Evde Çocuklarlyla Birlikte Okuma Yazmaya Hazırlı ve Matematik Etkinliklerini Gerçekleştirmelerine İlişkin Ortalama, En Yüksek, En Düşük ve Standart Sapma Değerleri

\begin{tabular}{lccccc}
\hline & $\mathbf{N}$ & En düşük & En yüksek & Ortalama & s \\
\hline $\begin{array}{l}\text { Yapılandırılmamış } \\
\text { Etkinlikler }\end{array}$ & 110 & 4 & 61 & 26.75 & 12.30 \\
$\begin{array}{l}\text { Yapılandırılmış } \\
\text { Etkinlikler }\end{array}$ & 110 & 9 & 64 & 38.02 & 12.88 \\
OYH Toplam & 110 & 14 & 124 & 64.76 & 23.12 \\
ÇEAD_Mat. & 110 & 24 & 60 & 40.25 & 7.65 \\
\hline
\end{tabular}


Okuma yazmaya hazırlık anketinden alınabilecek en yüksek puan 135'tir. Yapılandırılmamış etkinlikler alt boyutu için bu değer 66, yapılandırılmış etkinlikler için 69'dur. Tablo 5 incelendiğinde, çocukların okuma yazmaya hazırlık anketi toplam, yapılandırılmamış ve yapılandırılmış etkinlikler alt boyutlarına ilişkin toplam puan ortalamalarının orta düzeyde olduğu görülmektedir. Buna göre, ailelerin evde çocuklarının okuma yazmaya hazırlık becerilerini orta düzeyde desteklediği söylenebilir. Çocukların Evde Akademik Becerilerinin Desteklenmesi Ölçeği Matematik alt ölçeğinden alınabilecek en yüksek puan ise 68'dir. Çocukların bu testten aldıkları toplam puan ortalamaları incelendiğinde evde matematik becerilerinin orta düzeyde desteklendiği söylenebilir.

\section{Ailelerin Evde Çocuklarıyla Birlikte Okuma Yazmaya Hazırlık ve Matematik Etkinliklerini Gerçekleştirmeleri Üzerinde Bağımsız Değişkenlerin Etkisine İlişkin Bulgular}

$\mathrm{Bu}$ bölümde, çocukların cinsiyeti, yaşı, doğum sırası, okul öncesi eğitimi alma durumu ile okul öncesi eğitimi alma süresinin evde gerçekleştirilen okuma yazmaya hazırlık ve matematik etkinlikleri üzerindeki etkisi incelenmiştir. Elde edilen bulgular Tablo 6, 7, 8, 9 ve 10’da verilmiştir.

Tablo 6.

Cinsiyete Göre Mann Whitney U Testi Sonuçları

\begin{tabular}{lcccccc}
\hline & N & S.T. & S.O. & U & z & p \\
\hline Yapılandırılmamış & & & & & & \\
Etkinlikler & & & & & & \\
Kız & 56 & 3024.00 & 54.00 & 1204.000 & -.742 & .458 \\
Erkek & 47 & 2332.00 & 49.62 & & & \\
\hline Yapılandırılmıs & & & & & & \\
Etkinlikler & & & & & & \\
Kız & 56 & 3000.00 & 53.57 & 1228.000 & -.583 & .560 \\
Erkek & 47 & 2356.00 & 50.13 & & & \\
\hline ÇEABD Matematik & & & & & & \\
Kız & 56 & 3017.50 & 53.88 & 1210.500 & -.700 & .484 \\
Erkek & 47 & 2338.50 & 49.76 & & & \\
\hline Pr.05 & & & & & & \\
\hline
\end{tabular}

Analiz sonuçları, okuma yazmaya hazırlık anketi ve ÇEABD Matematik alt ölçeğinin ortalama puanlarında çocuğun cinsiyetine göre anlamlı bir farklılık olmadığını göstermektedir $(\mathrm{U}=1204,000 ; 1228,000 ; 1210,500, \mathrm{p}=, 458 ;, 560 ;, 484$, $\mathrm{p}>.05)$. 
Tablo 7.

Çocuğun Yaşına Göre Mann Whitney U Testi Sonuçları

\begin{tabular}{|c|c|c|c|c|c|c|}
\hline & $\mathbf{N}$ & S.T. & S.O. & $\mathbf{U}$ & $\mathbf{z}$ & $\mathbf{p}$ \\
\hline \multicolumn{7}{|c|}{ Yapılandırılmamış } \\
\hline \multicolumn{7}{|c|}{ Etkinlikler } \\
\hline $40-60$ ay & 27 & 1595.00 & 59.07 & 835.000 & -1.433 & .152 \\
\hline $60-80$ ay & 76 & 3761.00 & 49.49 & & & \\
\hline \multicolumn{7}{|c|}{ Yapılandırılmış } \\
\hline \multicolumn{7}{|c|}{ Etkinlikler } \\
\hline $40-60$ ay & 27 & 1665.50 & 61.69 & 764.500 & -1.961 & .060 \\
\hline $60-80$ ay & 76 & 3690.50 & 48.56 & & & \\
\hline \multicolumn{7}{|c|}{ ÇEABD Mat. } \\
\hline $40-60$ ay & 27 & 1563.000 & 57.89 & 867.000 & -1.194 & .232 \\
\hline $60-80$ ay & 76 & 3793.000 & 49.91 & & & \\
\hline
\end{tabular}

Analiz sonuçları, okuma yazmaya hazırlık anketi ve ÇEABD Matematik alt ölçeğinin ortalama puanlarında çocuğun yaşına göre anlamlı bir farklılık olmadığını göstermektedir ( $U=835,000 ; 764,500 ; 867,000, \mathrm{p}=, 152 ;, 060 ;, 232, \mathrm{p}>.05)$.

Tablo 8 .

Çocuğun Doğum Strasına Göre Kruskall Wallis-H Testi Sonuçlart

\begin{tabular}{|c|c|c|c|c|c|}
\hline & $\mathbf{N}$ & S.O. & sd & $\chi^{2}$ & p \\
\hline \multicolumn{6}{|c|}{ Yapılandırılmamış } \\
\hline \multicolumn{6}{|c|}{ Etkinlikler } \\
\hline En büyük & 21 & 58.17 & 3 & 1.063 & .786 \\
\hline En küçük & 47 & 52.71 & & & \\
\hline Tek & 20 & 60.65 & & & \\
\hline Ortanca & 22 & 54.23 & & & \\
\hline \multicolumn{6}{|c|}{ Yapılandırılmış } \\
\hline \multicolumn{6}{|c|}{ Etkinlikler } \\
\hline En büyük & 21 & 55.98 & 3 & 1.607 & .658 \\
\hline En küçük & 47 & 56.87 & & & \\
\hline Tek & 20 & 59.80 & & & \\
\hline Ortanca & 22 & 48.20 & & & \\
\hline \multicolumn{6}{|c|}{ ÇEABD Mat. } \\
\hline En büyük & 21 & 50.12 & 3 & 6.109 & .106 \\
\hline En küçük & 47 & 63.59 & & & \\
\hline Tek & 20 & 53.78 & & & \\
\hline Ortanca & 22 & 44.93 & & & \\
\hline
\end{tabular}


Analiz sonuçları, Okuma Yazmaya Hazırlık Anketi ve ÇEABD Matematik alt ölçeğinin ortalama puanlarının çocuğun doğum sırasına göre anlamlı bir şekilde farklılaşmadığını göstermektedir, $\chi 2(\mathrm{sd}=3, \mathrm{n}=110)=1,063 ; 1,607 ; 6,109, \mathrm{p}>0.05$.

Tablo 9.

Çocuğun Okul Öncesi Eğitim Alma Durumuna Göre Mann Whitney U Testi Sonuçlart

\begin{tabular}{lcccccc} 
& $\mathbf{N}$ & S.T. & S.O. & $\mathbf{U}$ & $\mathbf{z}$ & $\mathbf{p}$ \\
\hline $\begin{array}{l}\text { Yapılandırılmamış } \\
\text { Etkinlikler }\end{array}$ & & & & & \\
O.Ö.E. Alan & 26 & 1309.00 & 50.35 & 958.000 & -.231 & .818 \\
O.Ö.E. Almayan & 76 & 3944.00 & 51.89 & & & \\
\hline Yapılandırılmış & & & & & & \\
Etkinlikler & & & & & & \\
O.Ö.E. Alan & 26 & 1707.00 & 65.65 & 620.000 & -2.826 & .005 \\
O.Ö.E. Almayan & 76 & 3546.00 & 46.66 & & & \\
\hline ÇEABD Mat. & & & & & & \\
O.Ö.E. Alan & 26 & 1487.00 & 57.19 & 840.000 & -1.138 & .255 \\
O.Ö.E. Almayan & 76 & 3766.00 & 49.55 & & & \\
\hline
\end{tabular}

Analiz sonuçları, okuma yazmaya hazırlık anketi ortalama puanlarının yapılandırılmamış etkinlikler alt boyutu için çocuğun okul öncesi eğitimi alma durumuna göre anlamlı bir farklılık olmadığını göstermektedir ( $U=958,000, p=, 818$; p>.05). Öte yandan, çocukların yapılandırılmış etkinlikler ortalama puanlarının okul öncesi eğitimi alma durumuna göre farklılaştığ görülmektedir $(U=620,000, p=, 005$, $\mathrm{p}<.05)$. Okul öncesi eğitimi alan çocukların sıra ortalamaları $(65,65)$, okul öncesi eğitimi almayan çocukların sıra ortalamalarından $(46,66)$ daha yüksektir. Buna göre, daha önce okul öncesi eğitimi almış olan çocukların almayan çocuklara kıyasla evde aileleriyle birlikte okuma yazmaya ilişkin daha fazla yapılandırılmış etkinlik yaptıkları söylenebilir. Çocukların ÇEABD Matematik alt ölçeğinin puanlarının ise, okul öncesi eğitimi alma durumuna göre farklılık göstermediği görülmektedir (U=840,000, p=,255, p>.05).

Tablo 10.

Çocuğun Okul Öncesi Eğitim Alma Süresine Göre Kruskall Wallis-H Testi Sonuçlart

\begin{tabular}{lllllll}
\hline & N & \multicolumn{1}{c}{ S.O. } & sd & $\boldsymbol{\chi 2}$ & p & Anlaml fark \\
\hline $\begin{array}{l}\text { Yapılandırılmamış } \\
\text { Etkinlikler }\end{array}$ & & & & & & \\
Hiç almayan & 84 & 55.83 & 2 & 1.123 & .570 & \\
Bir yıl alan & 20 & 50.88 & & & & \\
İki yıl alan & 6 & 66.33 & & & & \\
\hline $\begin{array}{l}\text { Yapılandırılmış } \\
\text { Etkinlikler }\end{array}$ & & & & & & \\
Hiç almayan & 84 & 50.41 & 2 & 11.813 & .003 & $\begin{array}{l}\text { Hiç eğitim almayan ve } \\
\text { iki yll eğitim alan }\end{array}$ \\
\hline
\end{tabular}




\begin{tabular}{|c|c|c|c|c|c|c|}
\hline \multirow{2}{*}{$\begin{array}{l}\text { Bir yıl alan } \\
\text { İki yıl alan }\end{array}$} & \multirow{2}{*}{$\begin{array}{l}20 \\
6\end{array}$} & \multicolumn{4}{|l|}{66.25} & \multirow[t]{2}{*}{$\begin{array}{l}\text { Bir y1l eğitim alan ile iki } \\
\text { y1l eğitim alan }\end{array}$} \\
\hline & & 90.92 & & & & \\
\hline ÇEABD Mat. & & & & & & \\
\hline Hiç almayan & 80 & 53.51 & 2 & 2.558 & .278 & \\
\hline Bir y1l alan & 20 & 58.25 & & & & \\
\hline İki y1l alan & 6 & 74.25 & & & & \\
\hline
\end{tabular}

Analiz sonuçları, Okuma Yazmaya Hazırlık Anketi ortalama puanlarının yapılandırılmamış etkinlikler alt boyutu için çocuğun okul öncesi eğitimi alma süresine göre anlamlı bir şekilde farklılaşmadığını göstermektedir, $\chi 2(\mathrm{sd}=2, \mathrm{n}=110)$ $=1,123, \mathrm{p}>0.05$. Öte yandan, yapılandırılmış etkinlikler alt boyutu puanlarında anlamlı bir farklılık olduğu görülmektedir, $\chi 2(\mathrm{sd}=2, \mathrm{n}=110)=11,813, \mathrm{p}<0.05$. Anlamlı farkın hangi gruplar arasında olduğunun belirlenmesi için ikili Mann Whitney $U$ testi gerçekleştirilmiştir. Buna göre, hiç eğitim almayan ve 1 yıl eğitim alan çocukların yapılandırılmış etkinlikler alt boyutu puanlarına ait sıra ortalamalarının iki yıl eğitim alan çocuklardan daha düşük olduğu belirlenmiştir. Çocukların ÇEABD Mat. Testi puanlarının ise, okul öncesi eğitimi alma süresine göre anlamlı bir şekilde farklılaşmadığı görülmektedir $(\mathrm{sd}=2, \mathrm{n}=110)=2,558, \mathrm{p}>.05)$. Ancak çocukların sıra ortalamaları incelendiğinde, test puanlarının okul öncesi eğitimi alma süresi ile doğru orantılı bir şekilde arttığı belirlenmiştir.

Araştırmada son olarak ailelerin evde çocuklarıyla birlikte okuma yazmaya hazırlık etkinliklerini gerçekleştirme sıklıkları ve çocuklarının matematik becerilerini destekleme durumları arasındaki korelasyon hesaplanmıştır. Analiz sonuçları, çocukların evde okuma yazmaya hazırlık becerilerinin desteklenmesi ile matematik becerilerinin desteklenmesi arasında orta düzeyde pozitif ve anlamlı bir ilişki olduğunu göstermiştir (rho=.48, p<.01).

\section{Tartışma, Sonuç ve Öneriler}

Okul öncesi dönemdeki çocukların evde okuma yazmaya hazırlık ve matematik becerilerinin ne düzeyde desteklendiğini ortaya koymayı amaçlayan bu araştırmada, ailelerin okuma yazmaya hazırlık etkinliklerinden kesinlikle önemli ve gerekli buldukları etkinliklerin genellikle çocukların sözcük dağarcığını geliştirmeye yönelik olan etkinlikler oldukları görülmüştür. Evde sıklıkla yaptırdıkları etkinliklerin ise kesinlikle önemli ve gerekli gördükleri etkinlikler ile aynı etkinlikler oldukları belirlenmiştir. Bilinmeyen kelimeleri açıklamak, okunan hikâye hakkında sorular sorarak, hikâye hakkında konuşmasını teşvik etmek gibi etkinlikler, çocuğun temelde dil gelişimini destekleyerek okuma yazma sürecini olumlu yönde destekleyen etkinlikler olarak nitelendirilebilir (Korat, 2009). Sénéchal (2006) ve Hood ve ark.'nın (2008) araştırmaları bu düşünceyi destekler niteliktedir. Söz konusu araştırmalarda evde çocuklara kitap okuma etkinliklerinin gerçekleştirilmesinin çocukların sözcük farkındalığı geliştirdiğini saptanmıştır. Ailelerin hem önemli olduğunu düşündükleri 
hem de evde sıklıkla gerçekleştirdikleri bir diğer etkinliğin ise ismindeki harfleri gösterip tanıtmak olduğu görülmüştür. Okul Öncesi Eğitimi Programında okul öncesi dönemde evde ve okulda çocuğa harf öğretimi yapılmaması yönünde bir açıklamaya yer verilmiştir (MEB, 2013b). Bunun nedeni, çocukların okuma yazmayı ses temelli öğrenmeleridir. Harfleri tanıtırken sesleriyle ifade edilmediğinde okuma yazma süreci olumsuz etkilenebilir. Bununla beraber, çocuğu kendi ismini yazmaya teşvik etmenin çocuğun alfabeye, yazıya ilişkin farkındalığını geliştirmesi ve çocuğu yazmaya karşı motive etmesi açısından oldukça önemli olduğu düşünülmektedir. Welsch, Sullivan ve Justice'in (2003) araştırması bu düşünceyi destekler niteliktedir. Araştırmacılar, okul öncesi dönemdeki çocukların isimlerini yazmayı denemelerinin onların alfabe bilgisi ve yazı farkındalığı becerisini yordadığını ortaya koymuştur.

Ailelerin çocuklarla evde nadiren gerçekleştirdiklerini ifade ettikleri okuma yazmaya hazırlık etkinliklerinin ses ile ilgili etkinlikler olduğu görülmektedir. Bununla beraber, çoğu aile ses çalışmalarını kesinlikle gerekli ve önemli bulmadıklarını da belirtmiştir. Kafiyeli sözcükler üretme, ilk sesi değiştirerek sözcük üretme, hece sayısına göre el çırpma gibi ses çalışmaları, çocukların fonolojik farkındalık becerilerinin geliştirilmesi açısından önemli etkinliklerdendir. Öte yandan, sıkça yapılan etkinlikler incelendiğinde, tekerlemeli oyunlar oynamak, kafiyeli şarkılar söylemek gibi fonolojik farkındalık becerisinin kazanılmasına yönelik etkinliklere de rastlanmaktadır. Aileler, kelimelerdeki hecelere, seslere dikkat çekerek çocuğun düşünüp üretmesi gereken etkinlikleri okulda yapması gerektiğini düşünüyor olabilir. Bununla beraber, ses çalışmaları ile ilgili olarak öğretmenden yeterince öneri almıyor olabilir. Alan yazındaki çeşitli araştırmalar, ses çalışmalarının öğretmenler tarafından çok tercih edilmediğini göstermektedir. Ertürk, Gönen ve Pianta (2017) çalışmasında, çalışma grubundaki öğretmenlerin çok büyük bir bölümünün okuma yazmaya hazırlık çalışmaları kapsamında ses çalışmalarına yer vermediklerini bunun yerine kitap çalışmalarına yoğunluk verdiklerini saptamıştır. Dönmezler (2016) okul öncesi dönemde uygulanan okuma yazmaya hazırlık çalışmalarını incelediği araştırmasında benzer şekilde öğretmenlerin materyal gerektiren çizgi çalışması, kitap çalışması ve fotokopi kağıdı gibi yapılandırılmış etkinlikleri sıklıkla yaptığını ortaya koymuştur. Phillips, Menchetti ve Lonigan’a (2008) göre, fonolojik farkındalık becerisi desteklendiğinde çocukların ileride ses harf ilişkilerini anlamalarına ve okuma yazmayı daha kolay öğrenmelerine katkı sağlanmaktadır.

Ailelerin okuma yazmaya hazırlık ve matematik becerilerini evde orta düzeyde desteklediği belirlenmiştir. Bu bulgu, ailelerin okula hazır olmada kritik beceriler olan bu becerileri evde desteklenmenin önemine ilişkin farkındalıklarının düşük olmasından kaynaklanabilir. Gürşimşek (2003) de benzer şekilde ailelerin ev temelli katılımlarının yetersiz olduğunu saptamıştır. Çocukların hem söz konusu bu becerilerinin geliştirilmesi hem de ailelerde bu farkındalığın gelişmesi için gerçekleştirilmiş çeşitli müdahale araştırmalarına rastlamak mümkündür. Özen Altınkaynak (2016) geliştirdiği Aile Temelli Okum Yazmaya Hazırlık Programının 
araştırmada yer alan çocukların çeşitli dil becerilerine (alıcı, ifade edici, fonolojik farkındalık gibi) etkisini incelediği araştırmasında, çocukların evde aileleri tarafından okuma yazmaya hazırlık becerilerinin desteklenmesinin dil becerilerinde deney grubunda yer alan çocukların lehine bir gelişime neden olduğunu saptamıştır. Akıncı Coşgun ve Tezel Şahin'in (2018) araştırmasında ise, ev ortamında anne çocuk arasında etkileşime dayalı yapılan matematik etkinliklerinin annelerin erken matematik becerilerine yönelik bilgi ve farkındalıklarını geliştirdiği, bununla beraber ailelerin çocukların sayı ve işlem becerilerini desteklemeye yönelik birtakım etkinlikleri evde daha sık yaptıkları belirlenmiştir. Ailelerin çocuklara orta düzeyde destek sunmasının bir başka nedeni, öğretmenin bu becerilerin desteklenmesi sürecinde aile katılımını etkin bir şekilde kullanmaması olabilir. Nitelikli bir okul öncesi eğitimin önemli bileşenlerinden biri de aile katılımı çalışmalarıdır. Bu dönemde, aileler ile işbirliği içinde olmak ve aileleri çocuğun eğitimine katmak okul öncesi eğitimi öğretmenlerinin önemli sorumluluklarındandır (Aydoğan, 2017). Nokali, Bachman ve Votruba-Drzal'a (2010) göre; ailelerin öğretmenin sinıfta gerçekleştirdiklerinden haberdar olmaları evde sunulan desteği arttırmaktadır.

Ailelerin çocukların okuma yazmaya hazırlık ve matematik becerilerini destekleme düzeylerinin çocuğun cinsiyetine, yaşına ve doğum sırasına göre farklılık göstermediği belirlenmiştir. Okul öncesi eğitimi alma durumu ve süresi ise çocukların evde gerçekleştirdikleri yapılandırılmış okuma yazmaya hazırlık etkinlikleri üzerinde etkili olmuştur. Buna göre, çocuğu daha önce okul öncesi eğitimi almış aileler, almamış ya da daha kısa süre eğitim almış ailelere kıyasla evde çocuklarıyla daha çok yapılandırılmış okuma yazmaya hazırlık etkinliği gerçekleştirmektedir. Bu bulguya neden olarak, çocukları okul öncesi eğitimi alan ailelerin öğretmenin sınıf içi uygulamalarından etkileniyor olması gösterilebilir. Öğretmen yoğunlukla yapılandırılmış etkinlikler yoluyla çocukların okuma yazmaya hazırlık becerisini desteklemeye çalışıyor olabilir. Aileye sunduğu ev temelli çalışmalar da bu yönde kağıt kalem, çalışma sayfası şeklinde olabilir. Öğretmen, aileye yapılandırılmamış okuma yazmaya hazırlık etkinlikleri ile matematik becerisini destekleyecek etkinlik örneklerini göstermemiş olabilir. Alan yazında öğretmenlerin okuma yazmaya hazırlık ve matematik becerilerini desteklemede kullandıkları yöntemlerin yetersiz olduğuna dair araştırma bulgularına rastlamak mümkündür (Akbaba-Altun, ŞimşekÇetin ve Bay, 2014; Aktaş Arnas, Erden, Aslan ve Cömertpay, 2003; Taşkın, 2013).

Araştırmada çocukların okuma yazmaya hazırlık becerilerinin evde desteklenme durumu ile matematik becerilerinin evde desteklenme durumu arasında ilişki olduğu görülmüştür. Bu bulguya neden olarak, ailelerin evde okuma yazmaya hazırlık ve matematik becerilerinin desteklenmesine benzer şekilde önem vermesi gösterilebilir. Söz konusu iki beceri, çocuğu ilkokula hazırlamada önemli rol oynamaktadır (MEB, 2013a). Dolayısıyla, ailenin bir beceriye verdiği önemin diğerini de etkileyeceği bulgusu bu iki becerinin birbiri ile ilişkili olduğunu göstermesi açısından önemli bir bulgu olarak görülmektedir. 
Ailelerin çocuklara evde sundukları desteğin okuma yazmaya hazırlık ve matematik becerileri bağlamında orta düzeyde olduğu bulgusundan hareketle, öncelikle ailelere çocuğun gelişimi ve eğitiminde önemli bir rolü olduğunun farkında varması için bilgilendirme toplantıları düzenlenebilir. Çocuğa evde sunulan desteğin yalnızca yapılandırılmış etkinlikler yoluyla değil yapılandırılmamış etkinlikler yoluyla da yapılabileceği vurgulanabilir. Bunun yanı sıra, okuma yazmaya hazırlık ve matematik becerilerini evde nasıl destekleyebileceklerine ilişkin atölye çalışmaları düzenlenebilir. Evde gerçekleştirdikleri bazı rutinlerin çocuğun hangi gelişim alanını etkilediği üzerine tartışmalar yapılabilir. Aile katılımı çalışmaları kapsamında sınıf içi uygulamalardan haberdar olmaları sağlanabilir. Öğretmenlerin okuma yazmaya hazırlık ve matematik becerilerinin evde desteklenmesine ilişkin öneri geliştirebilecek yeterlilikte olmaları için seminerler düzenlenebilir.

\section{Kaynakça}

Akbaba Altun, S., Şimşek Çetin, Ö. \& Bay, D.N. (2014). Okuma yazmaya hazırlık çalışmalarına yönelik ögretmen görüşleri. Uşak Üniversitesi Sosyal Bilimler Dergisi, 7(1), 244-263.

Akıncı Coşgun, A. \& Tezel Şahin, F. (2018). Ev ortamında anne çocuk arasında etkileşime dayalı yapılan matematik etkinliklerinin annelerin erken matematik beceri farkındalı̆ğna etkisi. 2. Uluslararas1 Erken Müdahale Kongresi'nde sunulan bildiri, Antalya.

Aktaş Arnas, Y., Erden, Ş., Aslan, D. \& Cömertpay, B. (2003). Okul öncesi öğretmenlerin günlük programda yer verdikleri etkinlikler ve bu etkinliklerde kullandıkları yöntemler. G. Haktanır (Ed.) OMEP Dünya Konsey Toplantısı ve Konferansı Bildiri Kitabı (ss. 435-450) İstanbul: Ya-pa.

Altıparmak, S. (2010). Erken çocukluk döneminde ebeveynlerin okuma-yazmaya hazırlık konusundaki görüşleri (Yayınlanmamış yüksek lisans tezi). Orta Doğu Teknik Üniversitesi, Ankara.

Anders, Y., Rossbach H.G., Weinert, S., Ebert, S., Kuger, S. \& Lehrl, S. (2012). Home and preschool learning environments and their relations to the development of early numeracy skills. Early Childhood Research Quarterly, 27, 231-244.

Aydoğan, Y. (2017). Okul öncesi eğitimi kurumlarında aile katılımı. T. Güler Yıldız (Ed.) Anne baba eğitimi içinde (s. 102). Ankara: Pegem Akademi Yayıncılık.

Crnic, K. \& Lamberty, G. (1994). School readiness conference: Recommendations. Early Education and Development, 5(2), 165-76.

Dönmezler, E. (2016). Okul öncesi dönemde uygulanan okuma yazmaya hazırlık çalışmalarının öğretmen görüşlerine göre incelenmesi. Turkish Journal of Primary Education, 1, 42-53.

Ertürk Kara, H.G. \& Kılıç Çoksoyluer, Ş. (2017). Encouragement of early academic skills at home during early childhood period: Validity and reliability study of the EASYC Scale. Universal Journal of Educational Research, 5(12), 2294 - 2303.

Ertürk Kara, H.G. (2017). Aile kuramları. T. Güler Yıldız (Ed.) Anne baba eğitimi içinde (ss. 17-33). Ankara: Pegem Akademi Yayıncılık. 
Ertürk Kara, H.G., Gönen, M.S. \& Pianta, R. (2017). Öğretmen çocuk etkileşiminin niteliği ile çocukların öz düzenleme becerisi arasındaki ilişkinin incelenmesi. Hacettepe Eğitim Fakültesi Dergisi, 32(4), 880-895.

Fraenkel, J., Wanner, N. \& Huyn, H. (2012). How to design and evaluate research in education. New York, NY: McGraw-Hill.

Gürşimşek, I. (2003). Okul öncesi eğitime aile katılımı ve psikososyal gelişim. Kuram ve Uygulamada Ĕgitim Bilimleri, 3(1), 125-144.

Hood, M., Conlon, E. \& Andrews, G. (2008). Preschool home literacy practices and children's literacy development: A longitudinal analysis. Journal of Educational Psychology, 100, 252-271.

Huntsinger, C.S., Jose, P.B., Liaw, F.R. \& Ching, W.D. (1997). Cultural differences in early mathematics learning: a comparison of Euro-American, Chinese-American, and TaiwanChinese families. International Journal Behavioral Development, 21, 371-388.

Huntsinger, C.S., Jose, P.E. \& Luo, Z. (2016). Parental facilitation of early mathematics and reading skills and knowledge through encouragement of home-based activities. Early Childhood Research Quarterly, 37, 1-15.

Karasar, N. (2009). Bilimsel araştırma yöntemleri. Ankara: Nobel Yayınları.

Kleemans, T., Peeters, M., Segers, E. \& Verhoeven, L. (2011). Child and home predictors of early numeracy skills in kindergarten. Early Childhood Research Quarterly, 27,471-477.

Korat, O. (2009). Reading electronic books as a support for vocabulary, story comprehension and word reading in kindergarten and first grade. Computers \& Education, 55, 24-31.

Lefebvre, P., Trudeau, N. \& Sutton, A. (2011). Enhancing vocabulary, print awareness and phonological awareness through shared storybook reading with low-income preschoolers. Journal of Early Childhood Literacy, 11(4), 453-479.

LeFevre, J. A., Skwarchuk, S. L., Smith-Chant, B. L., Fast, L., Kamawar, D. \& Bisanz, J. (2009). Home numeracy experiences and children's math performance in the early school years. Canadian Journal of Behavioral Science, 41(2), 55-66.

Lynch, J., Anderson, J., Anderson, A. \& Shapiro, J. (2006). Parents' beliefs about young children's literacy development and parents' literacy behaviors. Reading Psychology, 27, $1-20$.

Milli Eğitim Bakanlığı (2013a). Okul öncesi eğitim programı ile bütünleştirilmiş aile destek ĕgitim rehberi (OBADER). Ankara: Milli Eğitim Bakanlığı Yayınları.

Milli Eğitim Bakanlığı (2013b). Okul öncesi eğitimi programı. Ankara: Milli Eğitim Bakanlığı Yayınları.

Nebrig, M.R. (2007). Parent and teacher perceptions of home activities to encourage emergent literacy (Doctoral dissertation), Lehigh University.

Nokali, N., Bachman, H. \& Votruba-Drzal, E. (2010). Parent involvement and children's academic and social development in elementary school. Child Development, 81(3), 9881005. 
Phillips, B., Menchetti, J.C. \& Lonigan, C.J. (2008). Successful phonological awareness instruction with preschool children lessons from the classroom. Topics in Early Childhood Special Education, 28(1), 3-17.

Sénéchal, M. (2006). Testing the Home Literacy Model: Parent involvement in kindergarten is differentially related to grade 4 reading comprehension, fluency, spelling, and reading for pleasure. Scientific Studies of Reading, 10, 59-87.

Sénéchal, M. \& LeFevre, J. (2002). Parental involvement in the development of children's reading skill: A 5-year longitudinal study. Child Development, 73(2), 445-460.

Snow, L.K. (2006). Measuring school readiness: Conceptual and practical considerations. Early Education and Development, 17(1), 7-41.

Taşkın, N. (2013). Okul öncesi dönemde matematik ile dil arasındaki ilişki üzerine bir inceleme (Yayınlanmamış doktora tezi). Hacettepe Üniversitesi, Ankara.

Uyanık, Ö. \& Kandır, A. (2010). Okul öncesi dönemde erken akademik beceriler. Kuramsal Ĕgitimbilim Dergisi, 3(2), 118-134.

Van Voorhis, F.L., Maier, M.F., Epstein, J.L. \& Lloyd, C.M. (2013). The impact of family involvement on the education of children ages 3 to 8: A focus on literacy and math achievement outcomes and social-emotional skills. Retrieved from https://www.mdrc.org/sites/default/files/The_Impact_of_Family_Involvement_FR.pdf.

Welsch, J.G., Sullivan, A. \& Justice, L.M. (2003). That's my letter! What preschoolers name writing representations tell us about emergent literacy knowledge, Journal of Literacy Research, 35, 757-776.

Wood, C. (2002). Parent-child preschool activities can affect the development of literacy skills. Journal of Research Reading, 25(3), 241-258.

\section{Extended Abstract}

Parent and school partnership has a critical role in early childhood education. School readiness must be held on a holistic view by parents and teachers (Crnic and Lamberty 1994; Snow 2006). Parents are excepted to support their children's early literacy and mathematics skills at home which will help their children being ready for school. Early literacy skills can be stated as oral language skills, alphabet knowledge, phonological awareness, Word knowledge, recognizing the words which start and last in same sound, detection of spoken words within written words. Math skills can be stated as size concepts, recognizing, naming, sorting, comparing, matching, grouping, numbers, addition, subtraction, division, modelling, geometry and visual logic, measuring and graph forming (Uyanık and Kandır, 2010). Children learn these skills with the help of the interactions at home and at school. So, parents should be aware of that they have a responsibility on children's school readiness. Teacher also should know about the parents, their needs so that they can make a lasting effect on children's learning. 
This study aims to examine parents' support of their children regarding early literacy and mathematics skills at home. Additionally, the effect of some variables such as gender, age, status of taking early childhood education, duration of early childhood education) on parents' support of children's early literacy and mathematics skills at home were examined. Determining the level of this support is thought to guide the parents to recognize the needs of the children in terms of early literacy and mathematic skills and also for teachers so that they can organize parent education according to the findings.

Screening model was preferred as research method. Sample of the study consist of 110 children who study at early childhood education centers in Aksaray and İstanbul. Convenient sampling method was preferred to determine the study group. Early Literacy Questionnaire, EASYC- Math and Personnel Information Form were used to collect the data. Descriptive analysis, Kruskal Wallis and Mann Whitney U tests and spearman correlation coefficient were run to analysis the data.

Findings of the study showed that parents mostly think that "describing the new words when reading to your child" item is certainly necessary and important within the early literacy activities (\%77). "Introducing the letters in their children's name" item followed this item (\%75.4). The parents stated that they mostly play with toys such as lego, playdough etc. The second activity which was mostly done by parents was "introducing the letters in their children's' name" (\%42.7). Parents also stated that they never do such activity like "want their child to change the first letter of a word for instance changing Murat as Surat" (\%59.1). and "ask the child if two words they told are rhyming or not" (\%51.8). When mean scores of children in Early Literacy Questionnaire and its sub dimensions were examined, it was seen that their scores were in medium level. According to this finding, it can be said that children are supported by their parents at home in medium level in terms of their early literacy skills. When EASYC- Math scores were examined, it was seen that children's mean scores were in medium level, as well. So, it can be said that children are supported by their parents at home in medium level in terms of their mathematics skills. Parents' support level at home didn't show a significant difference according to children's gender, age and order of birth. Status of taking early childhood education, duration of early childhood education variables made a significant effect on parents' support in structured activities sub dimension. Children who took early childhood education before had higher scores than children who haven't taken early childhood education before. And as the duration of early childhood education increases the structured activities scores increased. Lastly, a significant relation was determined between parents' support of their children's early literacy skills at home and parents' support of their children's mathematics skills at home.

In the light of the result that parents support of their children was in medium level, it can be suggested that meetings can be organized so that parents can be aware of how they have an important role in their children's development. In this meetings, the 
teacher should focus that not only structured activities but also non structured activities are helpful for children's development. Workshops can be organized for parents so that they can learn how to support their children's early literacy and math skills at home. Discussions can be made on daily routines' effect on developmental areas. Parent participation activities can be helpful for parents to learn about in class implementations. Seminars for teachers can be organized so that they can give suggestions to parents regarding how to support early literacy and math skills at home. 